\title{
Synthesis and characterization of Au-modified macroporous Ni electrocatalysts for
}

\section{alkaline water electrolysis}

Cristina González-Buch ${ }^{\mathrm{a}}$, Isaac Herraiz-Cardona ${ }^{\mathrm{b}}$, Emma M. Ortega $^{\mathrm{a}}$, Sergio Mestre ${ }^{\mathrm{c}}$, Valentín Pérez-Herranz ${ }^{\mathrm{a}^{*}}$

angeniería Electroquímica y Corrosión (IEC). Dep. Ingeniería Química y Nuclear.

Universitat Politècnica de València. Camino de Vera s/n. 46022 Valencia, Spain.

${ }^{\mathrm{b}}$ Institute of Advanced Materials (INAM), Universitat Jaume I, Castellón, Spain.

${ }^{c}$ Instituto Universitario de Tecnología Cerámica, Universitat Jaume I, Castellón, Spain.

*Corresponding author. Tel.: +34-96-3877632; fax: +34-96-3877639;

E-mail address: vperez@iqn.upv.es (V. Pérez-Herranz)

\begin{abstract}
$\mathrm{Au}$ nanoparticles (Au-NPs) were successfully synthesized and incorporated into the surface of a macroporous $\mathrm{Ni}$ electrode fabricated via galvanostatic electrodeposition at high current densities in order to produce hydrogen by means of alkaline water electrolysis. The developed electrodes were morphologically characterized by means of confocal laser scanning and field emission scanning electron microscopes. The electrocatalytic behaviour towards the hydrogen evolution reaction was studied by Tafel polarization curves and electrochemical impedance spectroscopy. It was clear that enlarging the real surface area of an electrode its catalytic activity was greatly enhanced. This improvement was further increased when Au-NPs were added to the macroporous Ni surface. In this case, the improvement was not only caused by enlarging the surface area but also by an improvement in the intrinsic catalytic activity of the alloy, as it was shown by the exchange current densities values, calculated from the real surface area.
\end{abstract}

Keywords: porous electrodes, Au nanoparticles, HER, alkaline water electrolysis, EIS. 


\section{Introduction}

Nowadays, everybody is concerned about the shortage of fossil energy resources, and the importance of hydrogen as a "green" energy carrier, because it can be obtained directly from renewable energy sources by water splitting. In order to build up a hydrogen energy cycle for an environmentally friendly and sustainable economy it is mandatory to provide hydrogen at low cost. For this purpose, alkaline water electrolysis is one of the most promising methods to produce clean and renewable hydrogen. Nevertheless, intensive research effort must be addressed in the reduction of both operating/energetic and initial investments to large-scale hydrogen production by means of this technique [1-5].

The energetic costs of alkaline electrolysers can be reduced by diminishing the overpotentials of both hydrogen and oxygen evolution reaction (HER, and OER, respectively), which take place during the water electrolysis process. Focussing on the HER, noble metals such as platinum and ruthenium are the most active materials. However, their high cost goes against the fulfilment of low initial investment for the electrodic material. For this reason, in the last years, a lot of work has been centred in the synthesis of active noble metal-free electrocatalysts [6].

The electrode performance toward HER can be improved by increasing its intrinsic catalytic activity and/or enlarging the material surface area. One of the most tested cathodes for alkaline water electrolysers are Ni-based alloys, such us NiCo [711], NiFe [12-15], NiMo [12,16-24], NiW [12,19,25,26], NiCu [27], NiAl [28,29], NiZn [30,31]; due to the relatively high catalytic activity of $\mathrm{Ni}$, and aiming at the synergism in the catalytic behaviour of the different components in the metallic alloy. Moreover, the development of nanoparticle catalysts has had a great interest because it not only allows using a small amount of material, but also provides a larger active 
surface area [32]. The metal nanoparticles need to be synthesized first and then assembled on the electrode [33]. The use of a macroporous electrode as a supporting material can reduce the dosage of noble metals [34]. This synthesis strategy has been successfully employed for HER. Amin et al. assembled dispersed silver nanoparticles (AgNPs) on titanium (Ti) substrates, yielding a better HER performance than bare platinum [32]. Abbaspour and Mirahmadi modified carbon paste electrodes with Fe and Ni mixed oxide nanoparticles. The obtained materials were renewable and showed a good stability. This, plus the low cost of Ni-ferrite NPs and facile large scale fabrication, postulated the Ni-ferrite NPs as a promising high-performance electrocatalyst for the HER in acidic media [35]. Abbaspour and Norouz-Sarvestani electrodeposited Au-Pd bimetallic nanoparticles on microwave irradiated carbon ceramic electrodes (MWCCE). A superior performance for HER was reported for the composite material in comparison with individual non-alloyed Au and Pd catalysts [36]. Hsieh et al. compared two different routes to deposit silver nanoparticles on oxidized carbon paper electrodes. From the results, microwave-assisted fabrication offered a fast and simple synthesis method with high activity for alkaline fuel cells with respect to the thermal reduction strategy [37]. Zheng and Mathe prepared single crystal tungsten oxide $\left(\mathrm{WO}_{3}\right)$ nanoparticles via a microwave-assisted method supported on carbon black. The overall experimental results revealed that the electrocatalytic activity for HER on $\mathrm{WO}_{3} / \mathrm{C}$ is six order magnitude higher than those obtained with carbon black in $1 \mathrm{M}$ $\mathrm{KOH}[38]$.

In the present work nanoparticles of gold have been successfully synthesized with a simple method and incorporated to a macroporous $\mathrm{Ni}$ electrodes with a thermal treatment. In this way, we combine the use of $\mathrm{Ni}$ as a support, which exhibits the best electrocatalytic activity among the non-noble materials and its highly porous structure, 
and $\mathrm{Au}$ nanoparticles which can further enhance the electrocatalytic activity. The presence of Au nanoparticles has been confirmed by means of field emission scanning electron spectroscopic microscopy (FE-SEM) and Energy-Dispersive X-Ray (EDX) analysis. The electrocatalytic behaviour towards HER was assessed by pseudo-steadystate polarization curves and electrochemical impendance spectroscopy (EIS) in alkaline media. 


\section{Experimental}

\subsection{Preparation of electrodes}

Macroporous Ni electrodes have been obtained by means of electrodeposition at high current densities as it is described in our previous work [10], and briefly summarised as follows. First, the stainless steel AISI 304 substrate material is polished until mirror surface and cleaned with $\mathrm{NaOH}$ (degreased) and $\mathrm{HCl}$ (stripping). Then, in order to increase the adherence of the stainless steel substrate, the electrode is anodically treated in $\mathrm{H}_{2} \mathrm{SO}_{4}$ and electrodeposited with a thin nickel deposit from a Wood's nickel solution. Afterwards, the electrodeposition at high current density (1 A $\mathrm{cm}^{-2}$ ) is carried out from a bath containing $48 \mathrm{~g} \mathrm{~L}^{-1} \mathrm{NiCl}_{2} \cdot 6 \mathrm{H}_{2} \mathrm{O}$ and $170 \mathrm{~g} \mathrm{~L}^{-1} \mathrm{NH}_{4} \mathrm{Cl}$, the $\mathrm{pH}$ of this solution was 4.5. A large-area graphite electrode of high purity was used as a counter-electrode, and an $\mathrm{Ag} / \mathrm{AgCl}$ (3 $\mathrm{M} \mathrm{KCl}$ electrolyte) electrode was used as reference. The experiments were carried out by means of an AUTOLAB PGSTAT302N potentiostat/ galvanostat. Then, the Au nanoparticles were synthesized and added to one of the developed electrode surface (Macroporous Ni-Au NPs).

In order to obtain Au nanoparticles, a $2.5 \cdot 10^{-4} \mathrm{M}$ tetrachloroauric acid solution was prepared and heated to $100{ }^{\circ} \mathrm{C} .25 \mathrm{~mL}$ of a $0.5 \mathrm{wt} . \%$ sodium citrate were added at the hot solution. The citrate ions are responsible for the reduction of $\mathrm{Au}$ (III) ions to $\mathrm{Au}$ (0) and also for being complexing agents of the formed nanoparticles. Thus, the nanoparticle colloidal suspension is stabilized.

The supporting macroporous Ni electrode was coated with gold slurry by dip coating. Prior to the coating, the gold suspension was modified to increase viscosity and lower surface tension by addition of Hydroxyethyl Cellulose (0.5 wt.\%) and BYK 347 (1 wt.\%). Then the electrode was dip coated four times allowing it to dry between the 
immersions. Finally, the electrode was treated thermally in a tubular furnace at $350{ }^{\circ} \mathrm{C}$ for 1 hour under a nitrogen atmosphere.

The particle size distribution of gold suspension was analyzed by Dynamic Light Scattering (Zetasizer Nano S90, UK). The surface morphology of the developed electrodes were studied by means of an OLYMPUS LEXT OLS3100-USS confocal laser scanning microscope, and A ZEISS ULTRA 55 FE-SEM coupled with an EDX analysis was used to observed the morphology and to confirm the presence of the Au nanoparticles on the electrode surface.

\subsection{Electrochemical measurements}

The electrocatalytic behaviour of the developed materials was studied by means of pseudo-steady-state polarization curves and EIS. These tests were performed in 30 wt. $\% \mathrm{KOH}$ previously deaerated by bubbling $\mathrm{N}_{2}$ during 15 minutes.

The pseudo-steady-state polarization curves consist of a potentiodynamic scan at $1 \mathrm{mV} \mathrm{s}^{-1}$, from a cathodic potential of $-1.6 \mathrm{~V}$ (vs. $\mathrm{Ag} / \mathrm{AgCl}$ ) until the equilibrium potential. These curves were performed at different temperatures from $30^{\circ} \mathrm{C}$ to $80{ }^{\circ} \mathrm{C}$. EIS measurements were accomplished after the corresponding polarization curves at 30 , 50 and $80{ }^{\circ} \mathrm{C}$, in the frequency range of $10 \mathrm{kHz}$ to $5 \mathrm{mHz}$, with ten frequencies per decade and a sinusoidal signal of $10 \mathrm{mV}$ peak-to-peak. The complex nonlinear least square (CNLS) fitting of the impedance data was carried out with the ZView 3.0 software package. 


\section{Results and discussion}

3.1 Nanoparticle and morphology characterization

The particle size distribution of Au nanoparticles in suspension shows a sharply monomodal conformation in the range of 10 and $50 \mathrm{~nm}$, as shown in Figure 1a. The characteristic parameters $d_{10}, d_{50}$ and $d_{90}$ were 14,20 and $31 \mathrm{~nm}$ respectively. The gold suspension was analyzed by SEM (Fig. 1b). It was observed a homogeneous distribution of spherical particles.

Figure 2 shows the FE-SEM images obtained by the back-scattered electrons signal at different magnifications. In Fig. 2a it can be observed the typical Ni spongelike macrostructure obtained by electrodeposition at high current densities, with spherical holes with diameters ranging between 100 and $200 \mu \mathrm{m}$, as previously reported [10,39-41]. In Fig. 2b, Au nanoparticles homogeneously distributed on top of $\mathrm{Ni}$ macrostructure can be distinguished as white spots. A 0.88 at.\% of Au onto the electrode surface was measured by EDX analysis. Additional dip coating cycles were carried out in order to increase the Au loading, nevertheless, the acidic environment of this procedure lead to lower Au aggregation and changes in the macrostructure as a consequence of $\mathrm{Ni}$ corrosion. Figure 2 also shows the 3D confocal laser micrographs before (Fig. 2c) and after (Fig. 2d) the Au NPs modification. Slight differences can be observed on the matrix of the electrode surface, which can be attributed to both the dip coating and following thermal treatment. Therefore, the Au NPs aggregation does not affect the overall macroporous morphology. 


\subsection{Polarization measurements}

The electrocatalytic behaviour towards the HER of the developed macroporous $\mathrm{Ni}$ electrode modified with $\mathrm{Au}$ nanoparticles (Macroporous Ni-Au NPs) and without modification (Macroporous Ni) was studied by means of pseudo-steady-state polarization curves and EIS and compared with a commercial smooth Ni electrode. These techniques allow obtaining the most relevant kinetic parameters and the real electrochemically active surface area, and then concluding about the intrinsic catalytic activity of the developed electrodes.

Figure 3 shows the polarization curves recorded in $\mathrm{KOH} 30 \mathrm{wt} . \%$ at $30^{\circ} \mathrm{C}$ and $80{ }^{\circ} \mathrm{C}$ on the investigated electrocatalysts: smooth $\mathrm{Ni}$, macroporous $\mathrm{Ni}$ and macroporous Ni-Au NPs. The information obtained from the Tafel polarization data demonstrates that the macroporous electrodes are more active for HER, showing the macroporous Ni$\mathrm{Au}$ NPs the best performance. Curves showed a classical Tafelian behaviour, indicating that the HER on these electrodes is purely kinetically controlled reaction and it can be described by using the Tafel equation [40-43]: $\eta=a+b \log j$, where $\eta(\mathrm{V})$ represents the overpotential responsible of the current density $j\left(\mathrm{~A} \mathrm{~cm}{ }^{-2}\right), b\left(\mathrm{~V}\right.$ decade $\left.{ }^{-1}\right)$ is the Tafel slope, and $a(\mathrm{~V})$ is the intercept, related to the exchange current density $j_{0}\left(\mathrm{~A} \mathrm{~cm}^{-2}\right)$ by the equation: $a=(2.3 R T) /(\alpha F) \times \log j_{0}$. In turn, the charge transfer coefficient, $\alpha$, can be obtained from the Tafel slope by using the relation: $b=-(2.3 R T) /(\alpha F)$, where $R$ is the gas constant and $F$, the Faraday constant. By fitting the linear part of the Tafel curves recorded on the developed electrodes these kinetic parameters were obtained. Another important parameter that it was obtained to evaluate the catalytic activity of the electrodes was the overpotential at a fixed current density of $-100 \mathrm{~mA} \mathrm{~cm}{ }^{-2}, \eta_{100}$. For an electrode, the lower the overpotential at a fixed current density, the lower the amount of 
energy required to produce a given amount of hydrogen, that is, the higher the catalytic activity of the electrode.

It is well known that HER in alkaline solution proceeds via the mechanism consisting of the formation of an adsorbed hydrogen intermediate, $M H_{a d s}$ (Volmer reaction, Eq. (1)), followed by an electrochemical (Heyrovsky reaction, Eq. (2)) and/or a chemical hydrogen desorption step (Tafel reaction, Eq. (3)):

$$
\begin{aligned}
& \mathrm{H}_{2} \mathrm{O}+\mathrm{M}+e^{-} \rightarrow \mathrm{MH}_{a d s}+\mathrm{OH}^{-} \\
& \mathrm{H}_{2} \mathrm{O}+\mathrm{MH}_{a d s}+e^{-} \rightarrow \mathrm{H}_{2}+\mathrm{M}+\mathrm{OH}^{-} \\
& \mathrm{MH}_{a d s}+\mathrm{MH}_{a d s} \rightarrow \mathrm{H}_{2}+2 \mathrm{M}
\end{aligned}
$$

where $M$ is a free site on the metal surface.

The kinetic parameters calculated from the polarization curves are shown in Table 1.

Table 1. Kinetic parameters of the HER obtained

\begin{tabular}{|c|c|c|c|}
\hline \multirow{2}{*}{ Catalyst } & \multicolumn{3}{|c|}{ Temperature $\left({ }^{\circ} \mathrm{C}\right)$} \\
\hline & 30 & 50 & 80 \\
\hline \multicolumn{4}{|l|}{ Smooth Ni } \\
\hline$b_{1}\left(\mathrm{mVV} \operatorname{dec}^{-1}\right)$ & 255.7 & 240.3 & 249.8 \\
\hline$b_{2}\left(\mathrm{mV} \operatorname{dec}^{-1}\right)$ & 97.9 & 107.5 & 171.4 \\
\hline$i_{0}\left(\mu \mathrm{A} \mathrm{cm} \mathrm{cm}^{-2}\right)$ & 0.07 & 0.44 & 4.77 \\
\hline$\alpha$ & 0.61 & 0.60 & 0.41 \\
\hline$\eta_{100}$ & 503.1 & 470.4 & 555.0 \\
\hline \multicolumn{4}{|c|}{ Macroporous Ni } \\
\hline$b\left(\mathrm{mV} \mathrm{dec}{ }^{-1}\right)$ & 101.1 & 114.3 & 127.5 \\
\hline$i_{0}\left(\mathrm{~mA} \mathrm{~cm} \mathrm{~cm}^{-2}\right)$ & 0.02 & 0.11 & 1.04 \\
\hline$\alpha$ & 0.59 & 0.56 & 0.55 \\
\hline$\eta_{100}$ & 348.2 & 347.1 & 252.8 \\
\hline \multicolumn{4}{|c|}{ Macroporous Ni-Au NPs } \\
\hline$b\left(\mathrm{mV} \operatorname{dec}^{-1}\right)$ & 137.7 & 158.9 & 202.7 \\
\hline$i_{0}\left(\mathrm{~mA} \mathrm{~cm} \mathrm{~cm}^{-2}\right)$ & 1.46 & 4.37 & 22.55 \\
\hline$\alpha$ & 0.44 & 0.40 & 0.35 \\
\hline$\eta_{100}$ & 249.2 & 211.8 & 130.2 \\
\hline
\end{tabular}
from the polarization curves and EIS recorded in $30 \mathrm{wt} . \% \mathrm{KOH}$ solution at different temperatures 
A single value of Tafel slopes were observed for the developed electrodes, in contrast with the polarization curves recorded on the smooth $\mathrm{Ni}$ electrode, which displays two potential-dependent regions related to the HER. The Tafel slopes at overpotentials less cathodic than approximately $-200 \mathrm{mV}\left(\mathrm{b}_{1}\right)$ are quite high, which may indicate the presence of some oxides on the surface of the Ni electrode $[12,44]$.

As it can be seen from Table 1, the Tafel slope values ranging between 98 and $138 \mathrm{mV} \mathrm{dec}{ }^{-1}$ at $30{ }^{\circ} \mathrm{C}$, close to the theoretical $120 \mathrm{mV} \mathrm{dec}{ }^{-1}$ and the charge transfer coefficient is around 0.5 , indicating that the HER on these electrodes takes place by means of the Volmer-Heyrovsky mechanism $[45,46]$. The macroporous Ni electrode modified with $\mathrm{Au}$ NPs shows the highest $j_{0}$ and the lowest $\eta_{100}$ values, showing the highest overall catalytic activity, better than those values reported by Qian et al. [47]. However, the catalytic activity evaluated with the parameters described above is related to the geometric electrode area and not to the real electrochemical area, therefore it can not conclude on the intrinsic catalytic activity of the developed electrodes. EIS permits to assess the real electrochemically active surface of the developed electrodes by giving the roughness factor, $r_{f}$, as the ratio between the double layer capacitance of a rough electrode and the double layer capacitance of a smooth electrode, which is $20 \mu \mathrm{F} \mathrm{cm}{ }^{-2}$ $[45,48]$.

Figures 4.a and 4.b show the Nyquist representation of the impedance response on the macroporous Ni and Macroporous Ni-Au NPs. This response is characterized by two semicircles, i.e. two time constants. The diameter of the semicircle obtained at high frequency is practically constant with the overpotential while the diameter of the semicircle obtained at lower frequencies diminishes as the overpotential applied increases. This is due to the fact that the adsorption process is facilitated and the chargetransfer process dominates the impedance response as the potential increases. Hence, 
having into account the values of $\alpha$ and the Tafel slopes determined from the polarization curves, and the information extracted from the EIS experiments, it can be concluded that the HER is controlled by the Volmer-Heyrovsky mechanism [46,49].

This impedance response was correctly modelled by the equivalent circuit of two time constants in series (2TS) proposed by Chen and Lasia [49], consisting of the solution resistance, $\mathrm{R}_{\mathrm{S}}$, in series two parallel CPE-R elements. This circuit connects the high frequency CPE-R element with the electrode porosity and low frequency CPE-R to the kinetics of the hydrogen evolution reaction. The double layer capacitance of a porous electrode is given by the expression of Brug [50]:

$C_{d l}=\left[Q_{2} /\left(\left(R_{S}+R_{p}\right)^{-1}+R_{c t}{ }^{-1}\right)^{\left(1-n_{2}\right)}\right]^{1 / n_{2}}$, where $\mathrm{Q}_{2}$ and $\mathrm{n}_{2}$ are the parameters of the constant phase element at low frequencies; $R_{p}$ is the resistance of the first CPE-R element related to the porosity and $\mathrm{R}_{\mathrm{ct}}$ is the resistance of the second CPE-R, which is related to the charge transfer resistance.

The parameters of the equivalent circuit were obtained by the adjustment of CNLS with the software Zview 3.0 and are shown in Table 2. According to the $\chi^{2}$ values and the concordance between the experimental (symbols) and the fitting (lines) data it can be concluded that the 2TS equivalent circuit correctly model the EIS response on the developed electrodes. With respect to the parameters related to the HF CPE-R element, $\mathrm{R}_{\mathrm{p}}$ slightly increase with the overpotential, while $\mathrm{Q}_{1}$ diminishes. This behaviour is associated to the porous response [51]. For the $\mathrm{LF}$ semicircle, both $\mathrm{Q}_{2}$ and $\mathrm{R}_{\mathrm{ct}}$ decrease with the overpotential which is consistent with the charge- transfer phenomenon.

The roughness factor values calculated from the double layer capacitance value for the developed electrodes are also included on Table 2. As can been observed both macroporous electrodes have a roughness factor in the same order of magnitude and the 
slightly differences may be due to the difference of the bubbles formed during the electrodeposition process.

In order to evaluate the intrinsic catalytic activity of the electrode is necessary to obtain the kinetic parameters related to the electrochemically active area and not to the geometric area. Therefore the exchange current densities values corrected with the roughness factor, $j_{0}$ ' were obtained for the developed macroporous electrodes and are plotted on Figure 5 in Arrhenius representation. As can be seen from this Figure, the Macroporous Ni-Au NPs electrode has $j_{0}$ ' values between one and two orders of magnitude higher than both nickel electrodes; manifesting his higher intrinsic catalytic activity.

\begin{tabular}{|c|c|c|c|c|c|c|c|c|}
\hline \multirow{2}{*}{ Catalyst } & \multicolumn{8}{|c|}{ Temperature $/{ }^{\circ} \mathrm{C}$} \\
\hline & \multicolumn{4}{|c|}{30} & \multicolumn{4}{|c|}{80} \\
\hline \multicolumn{9}{|l|}{ Macroporous Ni } \\
\hline$\eta / \mathbf{m V}$ & 0 & -63 & -112 & -162 & 0 & -56 & -105 & -153 \\
\hline$x^{2}$ & $1.35 \cdot 10^{-3}$ & $9.29 \cdot 10^{-4}$ & $5.93 \cdot 10^{-4}$ & $4.18 \cdot 10^{-4}$ & $1.41 \cdot 10^{-3}$ & $7.56 \cdot 10^{-4}$ & $5.97 \cdot 10^{-4}$ & $3.19 \cdot 10^{-4}$ \\
\hline$R_{S} / \Omega \mathrm{cm}^{2}$ & 0.44 & 0.44 & 0.45 & 0.45 & 0.25 & 0.25 & 0.26 & 0.26 \\
\hline$R_{p} / \Omega \mathrm{cm}^{2}$ & 0.63 & 0.51 & 0.49 & 0.51 & 0.12 & 0.12 & 0.14 & 0.16 \\
\hline$Q_{1} / \mathbf{m} \Omega^{-1} \mathbf{c m}^{-2} \mathbf{s}^{n}$ & 28.3 & 21.5 & 20.2 & 20.3 & 11.3 & 11.9 & 9.7 & 10.4 \\
\hline$n_{1}$ & 0.65 & 0.68 & 0.69 & 0.68 & 0.85 & 0.83 & 0.83 & 0.80 \\
\hline$R_{c t} / \Omega \mathbf{c m}^{2}$ & 182 & 99 & 60 & 34 & 20.3 & 16.5 & 9.07 & 3.75 \\
\hline$Q_{2} / \mathbf{m} \Omega^{-1} \mathbf{c m}^{-2} \mathbf{s}^{n}$ & 19.6 & 15.4 & 14.0 & 13.0 & 18.3 & 15.3 & 11.6 & 9.9 \\
\hline$n_{2}$ & 0.93 & 0.93 & 0.93 & 0.93 & 0.93 & 0.94 & 0.94 & 0.95 \\
\hline$C_{d l} / \mathrm{mF} \mathbf{c m}^{-2}$ & 14.8 & 11.1 & 10.0 & 9.3 & 12.3 & 11.2 & 8.4 & 7.4 \\
\hline$r_{f}$ & 742 & 557 & 499 & 465 & 615 & 560 & 421 & 372 \\
\hline \multicolumn{9}{|c|}{ Macroporous Ni-Au NPs } \\
\hline$\eta / \mathbf{m V}$ & 0 & -70 & -94 & -161 & 0 & -56 & -96 & -133 \\
\hline$x^{2}$ & $6.23 \cdot 10^{-4}$ & $2.58 \cdot 10^{-4}$ & $1.52 \cdot 10^{-4}$ & $6.07 \cdot 10^{-5}$ & $4.08 \cdot 10^{-4}$ & $1.75 \cdot 10^{-4}$ & $2.25 \cdot 10^{-4}$ & $1.65 \cdot 10^{-4}$ \\
\hline$R_{S} / \Omega \mathrm{cm}^{2}$ & 0.49 & 0.49 & 0.49 & 0.49 & 0.31 & 0.31 & 0.32 & 0.32 \\
\hline$R_{p} / \Omega \mathrm{cm}^{2}$ & 0.32 & 0.36 & 0.37 & 0.49 & 0.09 & 0.12 & 0.12 & 0.13 \\
\hline$Q_{1} / \mathbf{m} \Omega^{-1} \mathbf{c m}^{-2} \mathbf{s}^{n}$ & 23.5 & 18.0 & 16.7 & 19.8 & 10.7 & 11.3 & 9.6 & 6.7 \\
\hline$n_{1}$ & 0.68 & 0.68 & 0.68 & 0.65 & 0.86 & 0.81 & 0.81 & 0.83 \\
\hline$R_{c t} / \Omega \mathbf{c m}^{2}$ & 18.7 & 11.0 & 7.7 & 2.0 & 1.16 & 0.85 & 0.70 & 0.52 \\
\hline$Q_{2} / \mathbf{m} \Omega^{-1} \mathbf{c m}^{-2} \mathbf{s}^{n}$ & 16.0 & 10.5 & 8.7 & 6.5 & 22.6 & 16.1 & 12.9 & 11.2 \\
\hline$n_{2}$ & 0.92 & 0.93 & 0.94 & 0.98 & 0.86 & 0.89 & 0.89 & 0.89 \\
\hline$C_{d l} / \mathrm{mF} \mathbf{c m}^{-2}$ & 11.1 & 7.5 & 6.4 & 5.7 & 10.3 & 8.2 & 6.2 & 5.5 \\
\hline$r_{f}$ & 554 & 373 & 318 & 286 & 515 & 411 & 309 & 273 \\
\hline
\end{tabular}


Intrinsic activation energy $\left(E_{a}{ }^{\prime}\right)$ obtained at equilibrium potential $(\eta=0)$, with the exchange current densities corrected with respect to the roughness factor $\left(j_{0}{ }^{\prime}\right)$, is a widely used parameter in electrocatalysis to compare the catalytic activity of an electrode in a given electrolyte [52]. The lower the activation energy, the lower the energy requirements for hydrogen production. The $E_{a}$ ' is related to the kinetic coefficient by means of the Arrhenius equation: $k=A e^{-\frac{E_{a}{ }^{\prime}}{R T}}$. Due to the fact that the current density is proportionally related to the kinetic coefficient, the activation energy can be obtained by the following equation: $\log j_{0}{ }^{\prime}=A^{\prime}-\frac{E_{a}{ }^{\prime}}{2.303 \cdot R} \cdot \frac{1}{T}$, where $A^{\prime}$ is a constant in the operating conditions. Therefore, the intrinsic activation energy for the investigated electrodes can be obtained from the slope of the linear regression expressions showed on Figure 5. Both Ni electrodes present almost the same slope; it is the same intrinsic activation energy value, which is $75.0 \mathrm{~kJ} \mathrm{~mol}^{-1}$. On the other hand, the Macroporous Ni-Au Nps electrode manifests a significantly lower slope, resulting of a $51.9 \mathrm{~kJ} \mathrm{~mol}^{-1}$ intrinsic activation energy value. From these obtained values it is clear that the gold nanoparticles on the electrode surface improve the intrinsic catalytic activity of the Ni electrodes. 


\section{Conclusions}

$\mathrm{Ni}$ macroporous electrode was synthesized by galvanic deposition at high current densities and then modified with $\mathrm{Au}$ nanoparticles to evaluate their electrocatalytic behaviour towards the HER in alkaline media by means the pseudosteady-state polarization curves and EIS. Main results of this research allowed us to enhance that:

1. Au nanoparticles have been successfully synthesised and characterized, manifesting a homogeneous distribution of spherical particles.

2. Macroporous $\mathrm{Ni}$ electrodes have the typical macrostructure which corresponds to the Ni electrodes obtained at high current densities and the incorporation of $\mathrm{Au}$ nanoparticles seems not to affect the macrostructure.

3. From Tafel polarization data it is clear that the Macroporous Ni-Au NPs electrocatalyst shows higher catalytic activity towards the HER than the smooth and macroporous Ni electrodes.

4. EIS permits to obtain the electrochemically active area by means of the roughness factor value, $r_{f}$, and to conclude about the intrinsic catalytic activity by means the exchange current densities values corrected to the $r_{f}$. From these values it is clear that the Au nanoparticles improve the intrinsic catalytic activity of the Ni electrodes.

5. From both Tafel polarization and EIS data it is possible to conclude that HER on the Au-modified macroporous Ni electrocatalysts proceeds via the Volmer-Heyrovsky mechanism.

6. The intrinsic activation energy values allow also concluding that the $\mathrm{Au}$ nanoparticles improve the intrinsic catalytic activity of the macroporous $\mathrm{Ni}$ electrodes. 


\section{Acknowledgements}

The authors acknowledge the support of Generalitat Valenciana (PROMETEO/2010/023) and Universidad Politécnica de Valencia (PAID-06-10-2227).

We wish to thank the Electron Microscopy Service of the UPV. 


\section{References}

[1] Barbir F. Transition to renewable energy systems with hydrogen as an energy carrier. Energy 2009;34:308-12. doi:10.1016/j.energy.2008.07.007.

[2] Veziroğlu TN, Barbir F. Hydrogen: the wonder fuel. Int J Hydrogen Energy 1992;17:391-404.

[3] Bockris JO. A solar-hydrogen economy for U.S.A. Int J Hydrogen Energy 1983;8:323-40. doi:10.1016/0360-3199(83)90048-4.

[4] Mazloomi K, Gomes C. Hydrogen as an energy carrier: Prospects and challenges. Renew Sustain Energy Rev 2012;16:3024-33. doi:10.1016/j.rser.2012.02.028.

[5] Ganley JC. High temperature and pressure alkaline electrolysis. Int J Hydrogen Energy 2009;34:3604-11. doi:10.1016/j.ijhydene.2009.02.083.

[6] Safizadeh F, Ghali E, Houlachi G. Electrocatalysis developments for hydrogen evolution reaction in alkaline solutions - A Review. Int J Hydrogen Energy 2015;40:256-74. doi:10.1016/j.ijhydene.2014.10.109.

[7] Herraiz-Cardona I, Ortega EM, Vázquez-Gómez L, Pérez-Herranz V. Electrochemical characterization of a $\mathrm{NiCo} / \mathrm{Zn}$ cathode for hydrogen generation. Int J Hydrogen Energy 2011;36:11578-87. doi:10.1016/j.ijhydene.2011.06.067.

[8] Lupi C, Dell'Era A, Pasquali M. Nickel-cobalt electrodeposited alloys for hydrogen evolution in alkaline media. Int J Hydrogen Energy 2009;34:2101-6. doi:10.1016/j.ijhydene.2009.01.015.

[9] Herraiz-Cardona I, Ortega EM, Pérez-Herranz V. Impedance study of hydrogen evolution on $\mathrm{Ni} / \mathrm{Zn}$ and $\mathrm{Ni}-\mathrm{Co} / \mathrm{Zn}$ stainless steel based electrodeposits. Electrochim Acta 2011;56:1308-15. doi:10.1016/j.electacta.2010.10.093.

[10] González-Buch C, Herraiz-Cardona I, Ortega EM, García-Antón J, PérezHerranz V. Synthesis and characterization of macroporous Ni, Co and Ni-Co electrocatalytic deposits for hydrogen evolution reaction in alkaline media. Int $\mathrm{J}$ Hydrogen Energy 2013;38:10157-69. doi:10.1016/j.ijhydene.2013.06.016.

[11] Herraiz-Cardona I, González-Buch C, Valero-Vidal C, Ortega EM, PérezHerranz V. Co-modification of Ni-based type Raney electrodeposits for hydrogen evolution reaction in alkaline media. J Power Sources 2013;240:698-704. doi:10.1016/j.jpowsour.2013.05.041. 
[12] Navarro-Flores E, Chong Z, Omanovic S. Characterization of Ni, NiMo, NiW and $\mathrm{NiFe}$ electroactive coatings as electrocatalysts for hydrogen evolution in an acidic medium. J Mol Catal A Chem 2005;226:179-97. doi:10.1016/j.molcata.2004.10.029.

[13] de Giz MJ, Bento SC, Gonzalez ER. NiFeZn codeposit as a cathode material for the production of hydrogen by water electrolysis. Int $\mathrm{J}$ Hydrogen Energy 2000;25:621-6. doi:10.1016/S0360-3199(99)00084-1.

[14] Solmaz R, Kardaş G. Electrochemical deposition and characterization of NiFe coatings as electrocatalytic materials for alkaline water electrolysis. Electrochim Acta 2009;54:3726-34. doi:10.1016/j.electacta.2009.01.064.

[15] Ullal Y, Hegde AC. Electrodeposition and electro-catalytic study of nanocrystalline Ni-Fe alloy. Int $J$ Hydrogen Energy 2014;39:10485-92. doi:10.1016/j.ijhydene.2014.05.016.

[16] Raj IA. Characterization of nickel-molybdenum and nickel-molybdenum-iron alloy coatings as cathodes for alkaline water electrolysers. Int J Hydrogen Energy 1988;13:215-23. doi:10.1016/0360-3199(88)90088-2.

[17] Raj IA, Vasu KI. Transition metal-based hydrogen electrodes in alkaline solution - electrocatalysis on nickel based binary alloy coatings. J Appl Electrochem 1990;20:32-8. doi:10.1007/BF01012468.

[18] Huot JY, Trudeau ML, Schulz R. Low Hydrogen Overpotential Nanocrystalline Ni-Mo Cathodes for Alkaline Water Electrolysis. J Electrochem Soc 1991;138:1316. doi:10.1149/1.2085778.

[19] Fan C, Piron DL, Sleb A, Paradis P. Study of Electrodeposited NickelMolybdenum, Nickel-Tungsten, Cobalt-Molybdenum, and Cobalt-Tungsten as Hydrogen Electrodes in Alkaline Water Electrolysis. J Electrochem Soc 1994;141:382-7. doi:10.1149/1.2054736.

[20] Gennero de Chialvo MR, Chialvo AC. Hydrogen evolution reaction on smooth $\mathrm{Ni}(1-\mathrm{x})+\operatorname{Mo}(\mathrm{x})$ alloys $(0 \leq \mathrm{x} \leq 0.25)$. J Electroanal Chem 1998;448:87-93. doi:10.1016/S0022-0728(98)00011-4.

[21] Krstajić N V., Jović VD, Gajić-Krstajić L, Jović BM, Antozzi AL, Martelli GN. Electrodeposition of Ni-Mo alloy coatings and their characterization as cathodes for hydrogen evolution in sodium hydroxide solution. Int J Hydrogen Energy 2008;33:3676-87. doi:10.1016/j.ijhydene.2008.04.039. 
[22] Tasić GS, Maslovara SP, Zugic DL, Maksić AD, Kaninski MPM. Characterization of the $\mathrm{Ni}-\mathrm{Mo}$ catalyst formed in situ during hydrogen generation from alkaline water electrolysis. Int $\mathrm{J}$ Hydrogen Energy 2011;36:11588-95. doi:10.1016/j.ijhydene.2011.06.081.

[23] Marini S, Salvi P, Nelli P, Pesenti R, Villa M, Kiros Y. Stable and inexpensive electrodes for the hydrogen evolution reaction. Int $\mathrm{J}$ Hydrogen Energy 2013;38:11484-95. doi:10.1016/j.ijhydene.2013.04.159.

[24] Mckone JR, Sadtler BF, Werlang CA, Lewis NS, Gray HB. Ni - Mo Nanopowders for E ffi cient Electrochemical Hydrogen Evolution. ACS Catal 2013.

[25] Wang M, Wang Z, Guo Z, Li Z. The enhanced electrocatalytic activity and stability of NiW films electrodeposited under super gravity field for hydrogen evolution reaction. Int J Hydrogen Energy 2011;36:3305-12. doi:10.1016/j.ijhydene.2010.12.116.

[26] Oliver-Tolentino MA, Arce-Estrada EM, Cortés-Escobedo CA, Bolarín-Miro AM, Sánchez-De Jesús F, González-Huerta RDG, et al. Electrochemical behavior of NixW1-x materials as catalyst for hydrogen evolution reaction in alkaline media. J Alloys Compd 2012;536:S245-9. doi:10.1016/j.jallcom.2011.12.086.

[27] Solmaz R, Döner A, Kardaş G. The stability of hydrogen evolution activity and corrosion behavior of $\mathrm{NiCu}$ coatings with long-term electrolysis in alkaline solution. Int J Hydrogen Energy 2009;34:2089-94. doi:10.1016/j.ijhydene.2009.01.007.

[28] Dong H, Lei T, He Y, Xu N, Huang B, Liu CT. Electrochemical performance of porous Ni3Al electrodes for hydrogen evolution reaction. Int J Hydrogen Energy 2011;36:12112-20. doi:10.1016/j.ijhydene.2011.06.115.

[29] Wu L, He Y, Lei T, Nan B, Xu N, Zou J, et al. Characterization of porous Ni3Al electrode for hydrogen evolution in strong alkali solution. Mater Chem Phys 2013;141:553-61. doi:10.1016/j.matchemphys.2013.05.061.

[30] Sheela G, Pushpavanam M, Pushpavanam S. Zinc-nickel alloy electrodeposits for water electrolysis. Int J Hydrogen Energy 2002;27:627-33. doi:10.1016/S03603199(01)00170-7.

[31] Solmaz R, Kardaş G. Hydrogen evolution and corrosion performance of NiZn coatings. Energy Convers Manag 2007;48:583-91. 
doi:10.1016/j.enconman.2006.06.004.

[32] Amin MA, Fadlallah SA, Alosaimi GS. In situ aqueous synthesis of silver nanoparticles supported on titanium as active electrocatalyst for the hydrogen evolution reaction. Int $\mathbf{J}$ Hydrogen Energy 2014;39:19519-40. doi:10.1016/j.ijhydene.2014.09.100.

[33] Kiani A, Hatami S. Fabrication of platinum coated nanoporous gold film electrode: A nanostructured ultra low-platinum loading electrocatalyst for hydrogen evolution reaction. Int J Hydrogen Energy 2010;35:5202-9. doi:10.1016/j.ijhydene.2010.03.014.

[34] Solmaz R. Electrochemical preparation and characterization of C/Ni-NiIr composite electrodes as novel cathode materials for alkaline water electrolysis. Int J Hydrogen Energy 2013;38:2251-6. doi:10.1016/j.ijhydene.2012.11.101.

[35] Abbaspour A, Mirahmadi E. Electrocatalytic hydrogen evolution reaction on carbon paste electrode modified with $\mathrm{Ni}$ ferrite nanoparticles. Fuel 2013;104:575-82. doi:10.1016/j.fuel.2012.07.016.

[36] Abbaspour A, Norouz-Sarvestani F. High electrocatalytic effect of Au-Pd alloy nanoparticles electrodeposited on microwave assisted sol-gel-derived carbon ceramic electrode for hydrogen evolution reaction. Int $\mathrm{J}$ Hydrogen Energy 2013;38:1883-91. doi:10.1016/j.ijhydene.2012.11.096.

[37] Hsieh C-T, Pan C, Chen W-Y. Synthesis of silver nanoparticles on carbon papers for electrochemical catalysts. J Power Sources 2011;196:6055-61. doi:10.1016/j.jpowsour.2011.03.087.

[38] Zheng $\mathrm{H}$, Mathe $\mathrm{M}$. Hydrogen evolution reaction on single crystal WO3/C nanoparticles supported on carbon in acid and alkaline solution. Int $\mathrm{J}$ Hydrogen Energy 2011;36:1960-4. doi:10.1016/j.ijhydene.2010.11.052.

[39] Marozzi CA, Chialvo AC. Development of electrode morphologies of interest in electrocatalysis. Part 1: Electrodeposited porous nickel electrodes. Electrochim Acta 2000;45:2111-20. doi:10.1016/S0013-4686(99)00422-3.

[40] Herraiz-Cardona I, Ortega EM, García-Antón J, Pérez-Herranz V. Assessment of the roughness factor effect and the intrinsic catalytic activity for hydrogen evolution reaction on Ni-based electrodeposits. Int $J$ Hydrogen Energy 2011;36:9428-38. doi:10.1016/j.ijhydene.2011.05.047.

[41] Herraiz-Cardona I, Ortega EM, Vázquez-Gómez L, Pérez-Herranz V. Double- 
template fabrication of three-dimensional porous nickel electrodes for hydrogen evolution reaction. Int J Hydrogen Energy 2012;37:2147-56. doi:10.1016/j.ijhydene.2011.09.155.

[42] Domínguez-Crespo MA, Torres-Huerta AM, Brachetti-Sibaja B, Flores-Vela A. Electrochemical performance of $\mathrm{Ni}-\mathrm{RE}(\mathrm{RE}=$ rare earth) as electrode material for hydrogen evolution reaction in alkaline medium. Int $\mathbf{J}$ Hydrogen Energy 2011;36:135-51. doi:10.1016/j.ijhydene.2010.09.064.

[43] Southampton Electrochemistry Group. Instrumental Methods in Electrochemistry. Wiley; 1985.

[44] Domínguez-Crespo MA, Ramírez-Meneses E, Montiel-Palma V, Torres-Huerta AM, Dorantes Rosales H. Synthesis and electrochemical characterization of stabilized nickel nanoparticles. Int J Hydrogen Energy 2009;34:1664-76. doi:10.1016/j.ijhydene.2008.12.012.

[45] Lasia A, Rami A. Kinetics of hydrogen evolution on nickel electrodes. J Electroanal Chem Interfacial Electrochem 1990;294:123-41. doi:10.1016/00220728(90)87140-F.

[46] Azizi O, Jafarian M, Gobal F, Heli H, Mahjani MG. The investigation of the kinetics and mechanism of hydrogen evolution reaction on tin. Int $\mathbf{J}$ Hydrogen Energy 2007;32:1755-61. doi:10.1016/j.ijhydene.2006.08.043.

[47] Qian X, Hang T, Shanmugam S, Li M. Decoration of Micro-/Nanoscale Noble Metal Particles on 3D Porous Nickel Using Electrodeposition Technique as Electrocatalyst for Hydrogen Evolution Reaction in Alkaline Electrolyte. ACS Appl Mater Interfaces 2015;7:15716-25. doi:10.1021/acsami.5b00679.

[48] Rami A, Lasia A. Kinetics of hydrogen evolution on Ni-Al alloy electrodes. J Appl Electrochem 1992;22:376-82. doi:10.1007/BF01092692.

[49] Chen L, Lasia A. Study of the Kinetics of Hydrogen Evolution Reaction on Nickel-Zinc Powder Electrodes. J Electrochem Soc 1992;139:3214-9. doi:10.1149/1.2069055.

[50] Brug GJ, van den Eeden ALG, Sluyters-Rehbach M, Sluyters JH. The analysis of electrode impedances complicated by the presence of a constant phase element. J Electroanal Chem Interfacial Electrochem 1984;176:275-95. doi:10.1016/S00220728(84)80324-1.

[51] Hitz C, Lasia A. Experimental study and modeling of impedance of the her on 
porous Ni electrodes. J Electroanal Chem 2001;500:213-22. doi:10.1016/S00220728(00)00317-X.

[52] Trasatti S. Electrocatalysis: understanding the success of DSA®. Electrochim Acta 2000;45:2377-85. doi:10.1016/S0013-4686(00)00338-8. 


\section{LIST OF FIGURES}

Figure 1.a Particle size distribution of the gold suspension and b. SEM micrograph of the gold suspension.

Figure 2. FE-SEM images of Macroporous Ni-Au NPs electrode at 30 (a) and 20000 magnifications (b) and 3D confocal laser micrographs before (c) and after (d) the Au NPs modification.

Figure 3. Linear Tafel polarization curves recorded on the investigated electrocatalytic coatings in $30 \mathrm{wt} . \% \mathrm{KOH}$ solution at $30{ }^{\circ} \mathrm{C}$ (filled dots) and $80{ }^{\circ} \mathrm{C}$ (empty dots).

Figure 4. Nyquist representation of the impedance data obtained in 30 wt.\% $\mathrm{KOH}$ solution at $50^{\circ} \mathrm{C}$ for a. Macroporous Ni electrode and for b. Macroporous Ni-Au Nps.

Figure 5. Arrhenius representation for the investigated electrocatalytic coatings in 30 wt.\% KOH solution. 


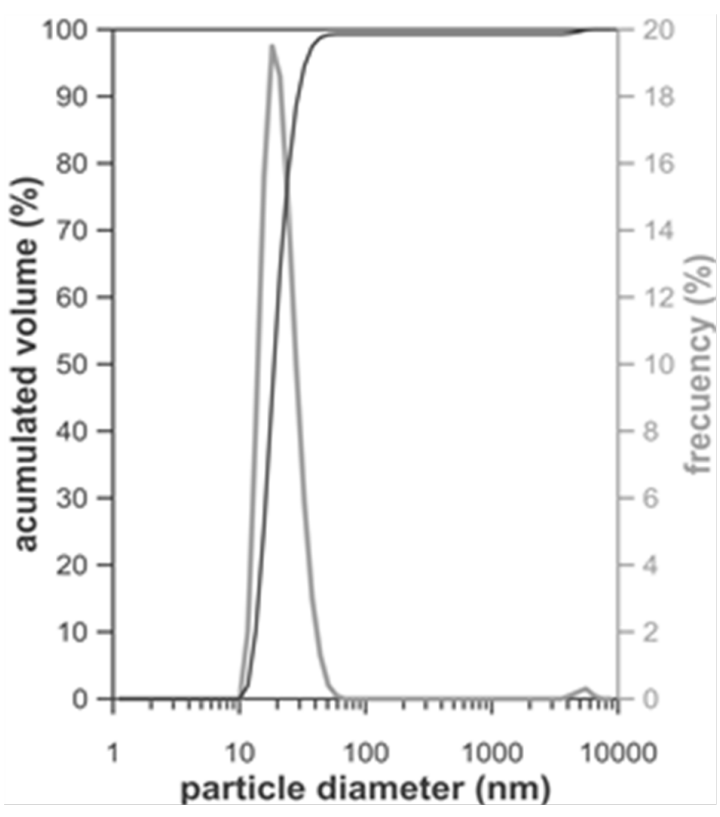

(a)

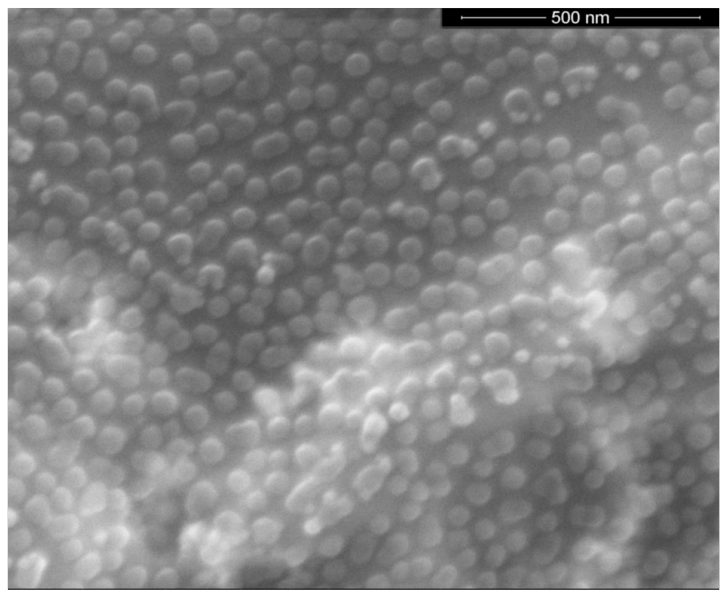

(b)

Figure 1.a Particle size distribution of the gold suspension and b. SEM micrograph of the gold suspension. 


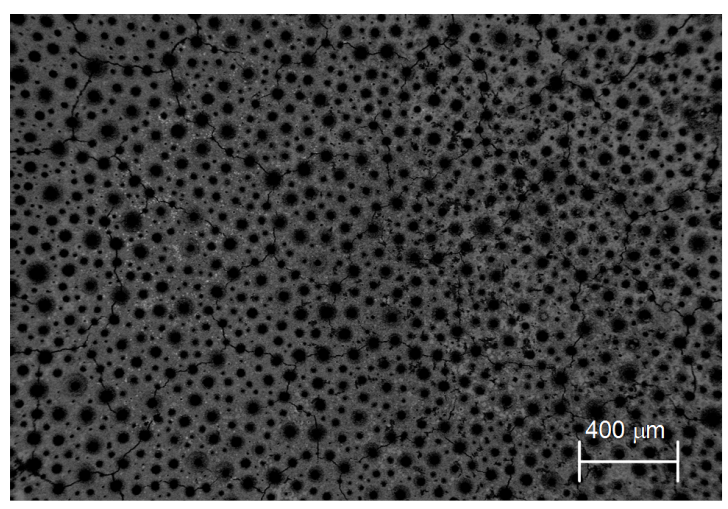

(a)

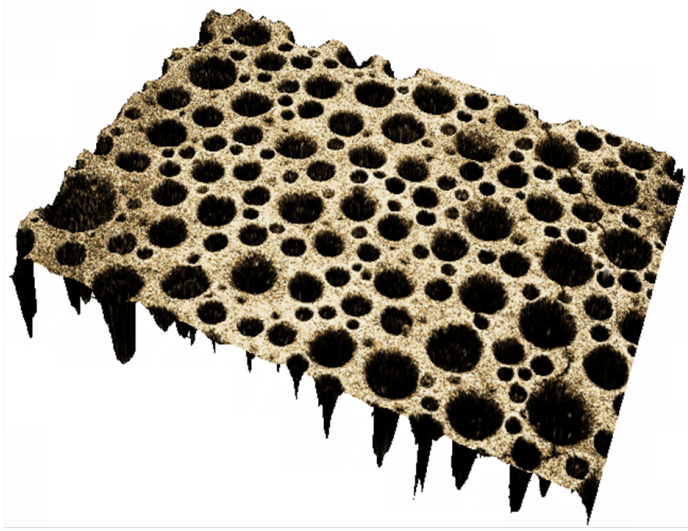

(c)

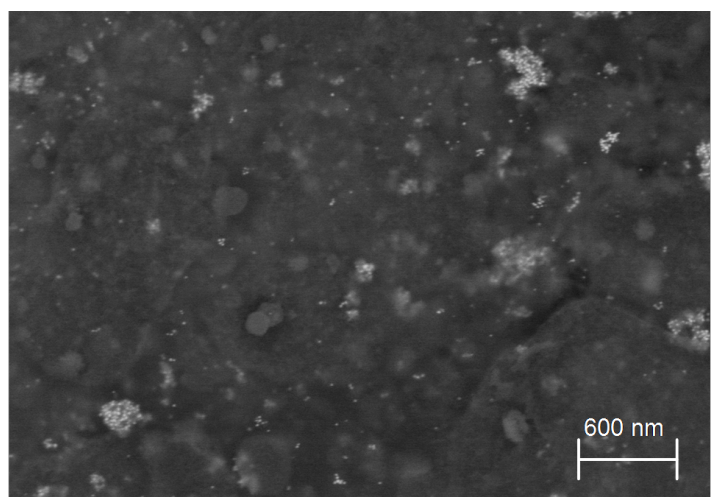

(b)

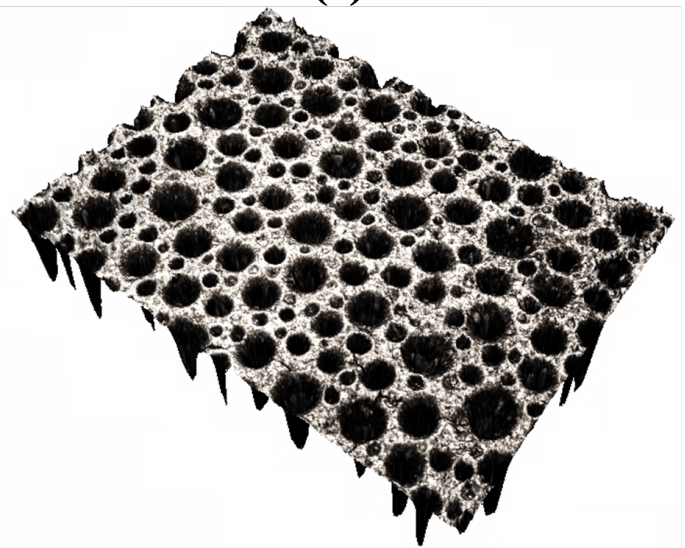

(d)

Figure 2. FE-SEM images of Macroporous Ni-Au NPs electrode at 30 (a) and 20000 magnifications (b) and 3D confocal laser micrographs before (c) and after (d) the Au NPs modification. 


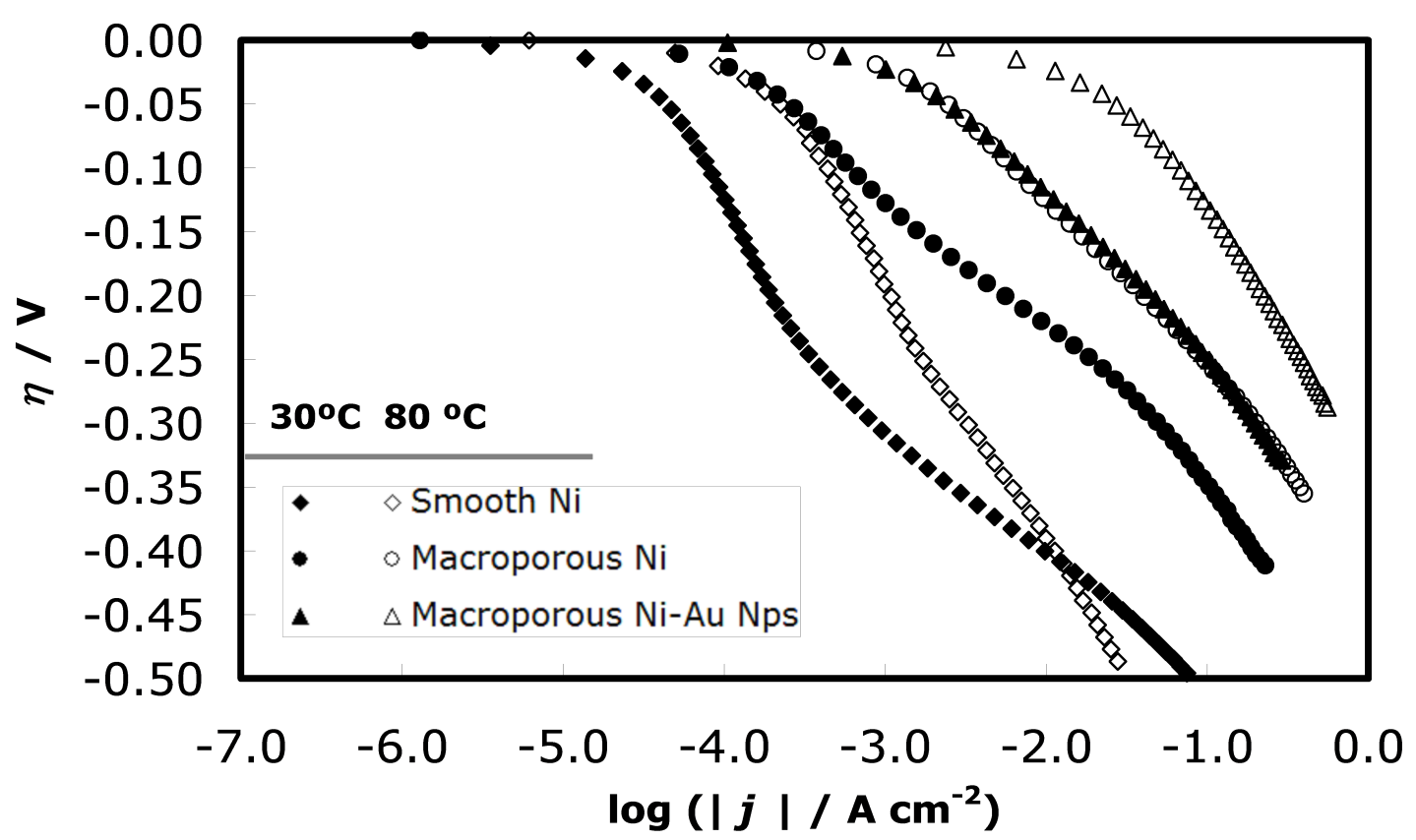

Figure 3. Linear Tafel polarization curves recorded on the investigated electrocatalytic coatings in $30 \mathrm{wt} . \% \mathrm{KOH}$ solution at $30^{\circ} \mathrm{C}$ (filled dots) and $80{ }^{\circ} \mathrm{C}$ (empty dots). 


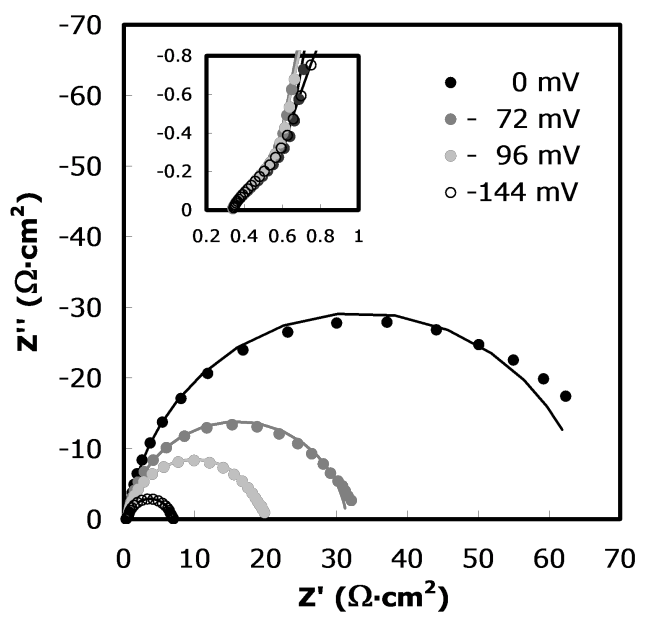

(a)

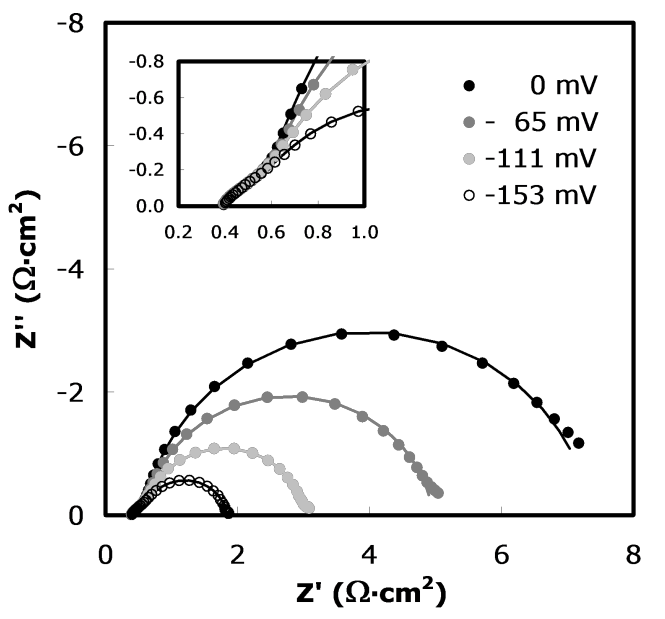

(b)

Figure 4. Nyquist representation of the impedance data obtained in 30 wt. $\% \mathrm{KOH}$ solution at $50^{\circ} \mathrm{C}$ for a. Macroporous Ni electrode and for b. Macroporous Ni-Au Nps. 


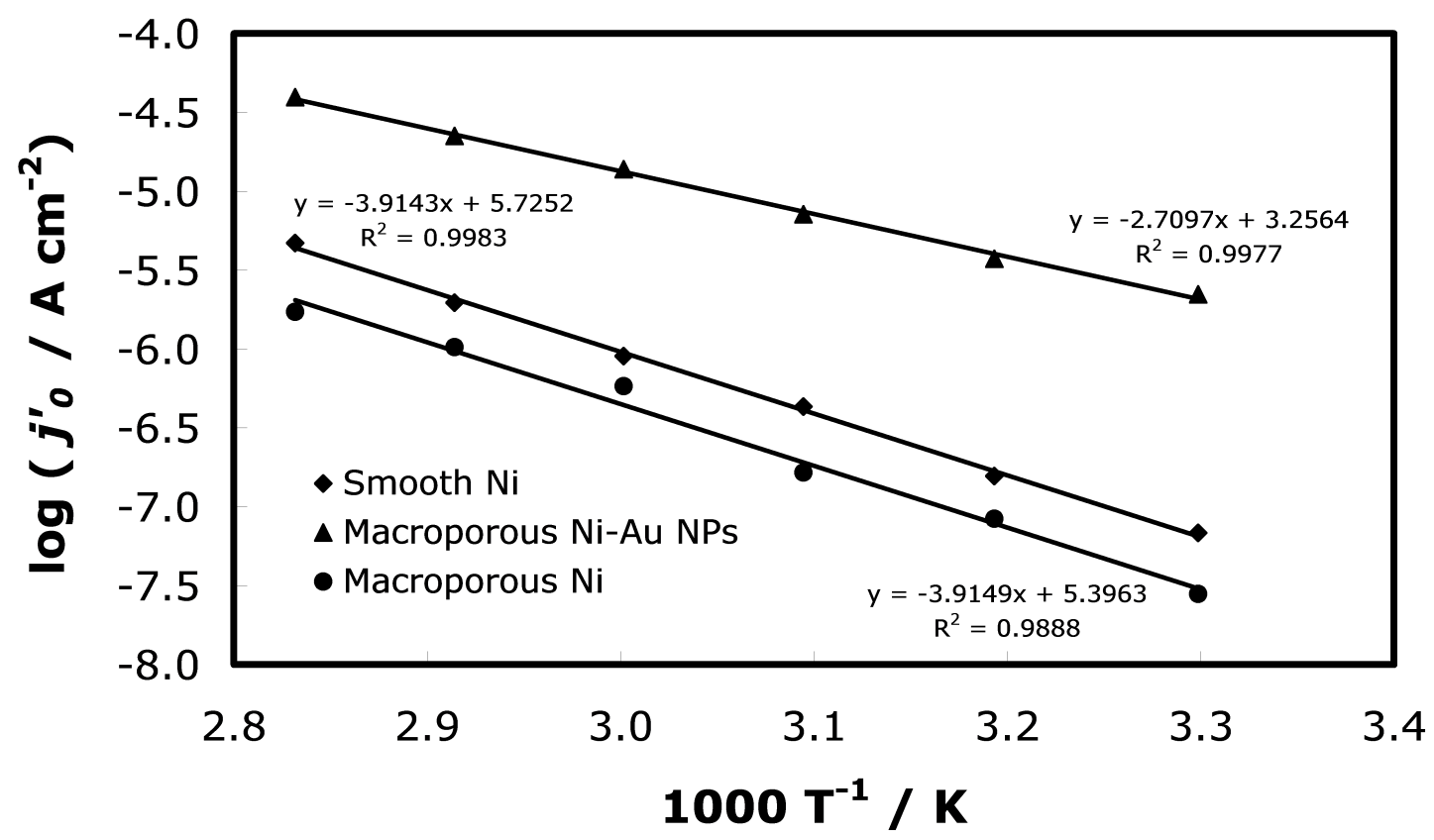

Figure 5. Arrhenius representation for the investigated electrocatalytic coatings in 30 wt.\% KOH solution. 